\title{
ELECCIONES EN SUECIA, 1991
}

\author{
M. ${ }^{a}$ VICTORIA GARCIA-ATANCE GARCIA \\ Profesora Titular de Derecho Constitucional \\ UNED
}


Revista de Derecho Político, núm. 35, 1992, pp. 329-336

\title{
ELECCIONES EN SUECIA
}

\author{
POR \\ M. ${ }^{a}$ VICTORIA GARCIA-ATANCE GARCIA \\ Profesora Titular Derecho Constitucional
}

UNED

El pasado día 15 de septiembre de 1991 marcó en Suecia el fin de una era de lo que había representado durante décadas el modelo sueco de bienestar.

Ya a finales de los años ochenta y de manera alarmante tras la primavera de 1989, la economía sueca incurrió en una grave recesión, con una elevada inflación de costes salariales y una productividad en estancamiento, como ha señalado Robert Taylor ${ }^{1}$.

Los problemas económicos preocuparon al Gobierno socialdemócrata de minoría existente desde septiembre de 1988, lo que le condujo a encargar un estudio especial sobre el poder y la democracia en Suecia. En dicho estudio se alcanzaría una conclusión que, en palabras del informe final publicado en julio de 1990, afirmaba: «El periodo de la historia de Suecia, caracterizado por una fuerte expansión del sector público, acuerdos centralizados a través de un compromiso entre trabajo y capital, y una planificación central, ha llegado a su fin». Ante estas expectativas, el reto principal con el que se enfrentaban los socialdemócratas era frente a los conservadores y liberales que decidieron su campaña electoral sobre un programa económico común, para dotar a Suecia de un nuevo comienzo, desde estos postulados: promover una economía de mercado fuerte, aumentar la competencia y estimular la propiedad individual y el ahorro.

Desde esta opción alternativa al modelo del bienestar sueco de cuño socialdemócrata, caben todas las tesis imaginables: desde que la op-

1 RoBert TAYLOR. Corresponsal del Financial Times en los países nórdicos, en ACtualidades de Suecia, núm. 383, junio 1991. 
ción conservadora suponga una rectificación correctora del modelo sueco propiciado por el partido socialdemócrata, hasta que sea muy difícil la resolución de los problemas con los que tengan que enfrentarse.

El sistema electoral sueco se caracteriza por ser proporcional, y en consecuencia, por producir Gobiernos de Coalición, como se desprende de la reciente historia electoral sueca de los últimos sesenta años en que la supremacía socialdemócrata obtuvo sólo en dos ocasiones la mayoría absoluta, debiendo en las demás confrontaciones electorales, gobernar los socialdemócratas en coalición.

Por otra parte, hay que relacionar el sistema de representación proporcional sueco con el 4 por 100 de los votos a nivel nacional para que un partido tenga acceso al Parlamento, o bien el 12 por 100 en una circunscripción electoral, como requisito imprescindible para acceder al Parlamento.

Sin perjuicio de reflejar posteriormente en un cuadro los resultados de las elecciones parlamentarias de 1976 a 1988, cabe señalar que los socialdemócratas gobernaron Suecia desde 1932 a 1976, a excepción de algunos meses de 1932, de una "Gran Coalición" de 1939 a 1945, y de una coalición con el Partido Agrario (centrista) de 1951 a 1957. En 1976, los Partidos de Centro, Conservador y Liberal lograron la mayoria parlamentaria, formando cuatro Gobiernos diferentes de coalición no socialista durante el periodo 1976-82. En las elecciones de 1982 el Partido Socialdemócrata reunió mayor número de escaños que aquellos tres partidos juntos, volviendo, pues, a formar Gobierno, si bien de condición minoritaria.

Tanto en las elecciones de 1985 como en las de 1988 perdieron algunos escaños, pero, no obstante, lograrian formar un nuevo Gobierno gracias al apoyo del Partido de Izquierda.

En 1988, un partido nuevo, Los Verdes, consiguió entrar en el Parlamento, cosa que no sucedía desde 1920.

En febrero de 1990, el Gobierno dimitió a raíz de una controversia en relación con la política económica, volviendo a asumir el cargo con posterioridad.

A continuación aportamos el cuadro (Cuadro 1) que refleja los resultados de las elecciones parlamentarias de 1976 a 1988, en los que se observa el claro predominio de la formación política socialdemócrata; de igual modo aportamos otro cuadro (Cuadro 2) en el que se representan, de manera genérica, los últimos resultados electorales socialdemócratas en los paises nórdicos. 
CUADRO 1

RESULTADOS DE LAS ELECCIONES PARLAMENTARIAS DE 1976 A 1988

\begin{tabular}{|c|c|c|c|c|c|c|c|c|c|c|}
\hline \multirow{2}{*}{ PARTIDOS } & \multicolumn{5}{|c|}{ PORCENTAJE DE VOTOS } & \multicolumn{5}{|c|}{ ESCAÑOS } \\
\hline & 1976 & 1979 & 1982 & 1985 & 1988 & 1976 & 1979 & 1982 & 1985 & 1988 \\
\hline \multicolumn{11}{|l|}{ Partidos no socialistas } \\
\hline $\begin{array}{l}\text { Partido Conservador } \\
\text { (Moderata Samlingspartiet, M) }\end{array}$ & 15,6 & 20,3 & 23,6 & 21,3 & 18,3 & 55 & 73 & 86 & 76 & 66 \\
\hline $\begin{array}{l}\text { Partido Liberal } \\
\text { (Folkpartiet Liberalerna, FP) }\end{array}$ & 11,1 & 10,6 & 5,9 & 14,2 & 12,2 & 39 & 38 & 21 & & 44 \\
\hline $\begin{array}{l}\text { Partido del Centro } \\
\text { (Centerpartiet, C) }\end{array}$ & 24,1 & 18,1 & 15,5 & $12,4^{1}$ & 11,3 & 86 & 64 & 56 & $44^{2}$ & 42 \\
\hline Partidos socialistas & & & & & & & & & & \\
\hline $\begin{array}{l}\text { Partido Socialdemócrata } \\
\text { (Sveriges Socialdemokratiska } \\
\text { Arbetareparti, S) }\end{array}$ & 42,7 & 43,2 & 45,6 & 44,7 & 43,2 & 152 & 154 & 166 & 159 & 156 \\
\hline $\begin{array}{l}\text { Partido de Izquierda } \\
\text { (Vänsterpartiet, V) }\end{array}$ & 4,8 & 5,6 & 5,6 & 5,4 & 5,9 & 17 & 20 & 20 & 19 & 21 \\
\hline Otros & & & & & & & & & & \\
\hline $\begin{array}{l}\text { Los Verdes de Suecia } \\
\text { (Miljöpartiet De Gröna, MP) }\end{array}$ & - & - & - & - & 5,5 & - & - & - & - & 20 \\
\hline
\end{tabular}

1 Incluido el 2,3 por 100 del Partido Demócrata Cristiano (Kristdemokratiska Samhällspartiet, KDS), que, en 1985, hizo campaña en las mismas listas del Partido Centrista.

2 Incluido el escaño del KDS. 


\section{CUADRO 2}

\section{ÚLTIMOS RESULTADOS ELECTORALES SOCIALDEMOCRATAS EN LOS PAISES NORDICOS}

\begin{tabular}{lcc}
\hline PAlSES & PORCENTAJE & AÑOS \\
\hline Suecia & 43,2 & 1988 \\
Noruega & 34,3 & 1989 \\
Dinamarca & 29,9 & 1988 \\
Finlandia & 22,1 & 1991 \\
Islandia & 15,5 & 1991 \\
\hline
\end{tabular}

Como es constatable la Socialdemocracia ha experimentado un claro retroceso electoral en los Países Nórdicos más acentuado en los últimos años, y que desembocará en el vuelco experimentado en Suecia el pasado día 15 de septiembre de 1991, y con él, el fin del famoso modelo socialdemócrata sueco. Desde esta perspectiva, Suecia asume un modelo político, en principio, más inestable, en el que la Socialdemocracia no ocupa el lugar preponderante que disfrutó durante decenios. No es en todo caso, la primera vez que los socialdemócratas pierden el poder a manos de los conservadores si se recuerdan los resultados de 1976 y 1982.

El resultado electoral se va fraguando, en todo caso ya en octubre de 1990, en que dos fuerzas políticas de signo no socialdemócrata, conservadores y liberales, formulaban un programa de gobierno conjunto que básicamente seguia los siguientes postulados: reducción de impuestos y gasto público; privatización de algunos sectores claves de la economía y liberalizar muchos de los controles impuestos a ésta; adhesión de Suecia a la CE y explotación de centrales nucleares. Esta coalición liderada por Carl Bildt, jefe de los conservadores, y Bengt Westerberg, líder de los liberales, se pronunció en declaración conjunta, respecto a la acción de las seis medidas políticas mencionadas con anterioridad, y como contrapunto a las propuestas del programa socialdemócrata.

Su aspiración a conseguir formar una mayoría no socialista en el Riksdag se vería culminada al integrarse asimismo en la alianza conserva- 
dora-liberal una tercera fuerza política no socialista: el Partido del Centro, a pesar de que tantos conservadores como liberales habian reprochado reiterativamente a su lider Olof Yohansson sus claras discrepancias politicas en materia de: economía, CE y energía.

El último socio en esta coalición no socialdemócrata es el Partido Demócrata Cristiano que ya había formado en otra legislatura una alianza con el Partido Centrista. Este partido con su carismático líder Alf Svensson subió en las encuestas de opinión pública muy ostensiblemente con la defensa de sus postulados sobre la familia, la naturaleza y la moral.

Entre estas cuatro formaciones han derrotado a los socialdemócratas, aunque no han conseguido la mayoría absoluta (ver Cuadro 3), toda vez que les faltan siete escaños para ello; sin embargo, si que han logrado la mayoría suficiente -169 escaños frente a los 156 del bloque de la izquierda - para que Carl Bildt pueda formar gobierno minoritario.

\section{CUADRO 3}

RESULTADOS DE LAS ELECCIONES SUECAS DE SEPTIEMBRE DE 1991

\begin{tabular}{lccc}
\hline PARTIDOS & PoRCENTAJE & DifeRENCIAS & ESCAÑOS \\
\hline Conservadores & 21,7 & $(+3,4)$ & 79 \\
Liberales & 9,2 & $(-3,0)$ & 34 \\
Centro & 8,0 & $(-3,3)$ & 29 \\
Democristianos & 7,3 & $(+4,4)$ & 27 \\
Verdes & 3,4 & $(-2,1)$ & 0 \\
Nueva Democracia & 6,5 & & 24 \\
Socialdemócratas & 37,0 & $(-5,3)$ & 139 \\
Izquierda & 4,7 & $(-0,9)$ & 17 \\
\hline
\end{tabular}




\section{PROGRAMA DE GOBIERNO}

A tenor de tales resultados, en fecha 4 de octubre de 1991, se procedería a la formación del nuevo Gobierno e investidura del Primer Ministro Carl Bildt en el Parlamento.

En su discurso de investidura aludirá al deseo de su gobierno de acometer una vigorosa renovación de Suecia, de conformidad con los deseos del electorado.

A tal fin aludiria a cuatro objetivos principales que predominarian en su mandato:

- La integración total de Suecia en la cooperación europea, a través de su ingreso en la Comunidad Europea.

- La quiebra del estancamiento económico del país y restablecimiento del desarrollo económico y empresarial con una economia fuerte.

- El mejoramiento del sistema de bienestar y protección social a través de la Revolución de la Libre Elección en el campo de la politica del bienestar.

- La creación de un desarrollo sólido, duradero y a largo plazo conducente a una sociedad de aire puro, agua limpia, lagos vivos y bosques.

En definitiva, el Gobierno del 4 de octubre de 1991 de Bildt ha apostado por una década de 1990 de cambios y renovación en Suecia. 